\title{
KEKUATAN FIBERGLASS REINFORCED PLASTIC (FRP) SEBAGAI BAHAN GADING KAPAL KAYU
}

\section{The Strength of Fiberglass Reinforced Plastic (FRP) as a Frame Material for Wooden Boat}

\author{
Alamsyah $^{1, \text { a }}$, Rodlian Jamal Ikhwani ${ }^{1, b}$, Taufik Hidayat ${ }^{1, \mathrm{c}}$, dan Suardi ${ }^{1, \mathrm{~d}}$ \\ ${ }^{1}$ Institut Teknologi Kalimantan, Jl. Soekarno-Hatta KM. 15, Karang Joang, Balikpapan, Kalimantan Timur, Indonesia \\ e-mail: aalamsyah@lecturer.itk.ac.id; bjamal@lecturer.itk.ac.id; 'taufik.hidayat@lecturer.itk.ac.id; ${ }^{\mathrm{d}}$ suardi@lecturer.itk.ac.id
}

\begin{abstract}
Abstrak
Penggunaan baja untuk menggantikan kayu Bitti sebagai bahan konstruksi gading kapal kayu dinilai tidak praktis karena melalui proses pembentukan dan pemeliharaan, sehingga penggunaan bahan lain seperti FRP sangat penting. Penelitian ini bertujuan untuk mengetahui ukuran dan bentuk penampang bahan FRP yang sesuai sebagai pengganti gading kayu ditinjau dari segi kekuatan. Metode yang digunakan yaitu elemen hingga (FEM) dan dianalisis menggunakan metode eksperimen numerik pada software. Penelitian ini bersifat kualitatif dengan mengoptimalkan bahan FRP dengan bentuk penampang I beam, I beam+flange, box of hole beam, $T$ beam, dan $U$ beam+flange sebagai pengganti bahan kayu Bitti. Hasil penelitian menunjukkan gading kayu Bitti memiliki elastisitas $(\mathrm{E})=9534.02 \mathrm{MPa}$ dan momen inersia penampang $(\mathrm{I})=2197 \times 10^{4} \mathrm{~mm}^{4}$ terjadi tegangan maksimum $(\sigma \mathrm{k})=7.682 \mathrm{~N} / \mathrm{mm}^{2}$ dan lendutan maksimum $(\delta)=0.1 \mathrm{~mm}$, untuk faktor keamanan gading kayu Bitti $(\mathrm{Sf})=1.28$, sedangkan bahan FRP pengganti gading kayu dengan nilai $(\mathrm{E})=69000 \mathrm{MPa}$ dapat digunakan penampang $I$ beam dengan nilai $I=316 \times 10^{4} \mathrm{~mm}^{4}$, $I$ beam+flange dengan nilai $I=288 \times 10^{4} \mathrm{~mm}^{4}$, box of hole beam dengan nilai $I=317 \times 10^{4} \mathrm{~mm}^{4}$, $T$ Beam dengan nilai $I=478 \times 10^{4} \mathrm{~mm}^{4}$, serta $U$ beam+flange dengan nilai $I=375 \times 10^{4} \mathrm{~mm}^{4}$, terjadi tegangan maksimum $(\sigma \mathrm{k})=52.00 \mathrm{~N} / \mathrm{mm}^{2}$ dengan lendutan maksimum $(\delta)<0.082 \mathrm{~mm}$ dan faktor keamanan $(\mathrm{Sf})=1.28$. Bahan FRP pengganti kayu gading membutuhkan momen inersia penampang sebesar 1/7 1/5 kali lebih kecil dari momen inersia penampang kayu gading dengan elastisitas tujuh kali lebih besar dari kayu gading. Nilai ini dapat dijadikan patokan untuk ukuran kapal di atas ataupun di bawah 70 GT ketika akan menggunakan bahan FRP sebagai pengganti gading kayu.
\end{abstract}

Kata kunci: gading; kapal kayu; fiberglass reinforced plastic; kayu bitti

\begin{abstract}
The use of steel to replace Bitti wood as a frame construction material of wooden ship is not practical due to forming and maintenance issues, so the use of other material such as FRP is essential. The purpose of this research was to determine the size and shape of a cross section of FRP materials suitable as a replacement for wood frame in terms of strength. The method used in the research was the finite element method (FEM), and the analysis was performed using numerical experimental method with software. The research was a qualitative study that optimized FRP materials with several forms of cross section (I beam, I beam + flange, Box of hole beam, $T$ beam, and $U$ beam + flange to replace the Bitti wood (vitex cofassus reinw). The results showed that the
\end{abstract}


frame of Bitti wood had an elasticity (E) of $9534.02 \mathrm{MPa}$ and the moment of inertia of the cross section (I) was $2197 \times 10^{4} \mathrm{~mm}^{4}$. There was a maximum stress $(\sigma \mathrm{k})$ of $7.682 \mathrm{~N} / \mathrm{mm}^{2}$ and a maximum deflection $(\delta)$ of $0.1 \mathrm{~mm}$. The safety factor of Bitti wood frame (Sf) was 1.28. Meanwhile, for FRP materials as the replacement of wood frame, the E value was $69000 \mathrm{MPa}$ with several forms of cross section: I beam with an I value of $316 \times 10^{4} \mathrm{~mm}^{4}$, I beam + flange with an I value of $288 \times 10^{4} \mathrm{~mm}^{4}$, box of hole beam with an I value of $317 \times 10^{4} \mathrm{~mm}^{4}$, T beam with an I value of $478 \times 10^{4} \mathrm{~mm}^{4}$, and $U$ beam + flange with an I value of $375 \times 10^{4} \mathrm{~mm}^{4}$. There was a maximum stress $(\sigma \mathrm{k})$ of $52.00 \mathrm{~N} / \mathrm{mm}^{2}$ and a maximum deflection $(\delta)<0.082 \mathrm{~mm}$ where $(\mathrm{Sf})=1.28$. The FRP material for frame wood replacement requires a moment of inertia of 1/7 1/5 times smaller than the moment of inertia of frame with an elasticity of 7 times greater than frame of wood. This value can be used as a benchmark for ship sizes above or below 70 GT when using FRP material as a replacement for wood frame.

Keywords: frame; wooden boat; fiberglass reinforced plastic; bitti wood

\section{PENDAHULUAN}

Salah satu warisan maritim yang paling penting dari Indonesia adalah kapal kayu (phinisi) (Abbas, 2001). Intensitas perdagangan antar pulau-pulau kecil di Indonesia sangat tinggi, sehingga angkutan perairan merupakan bentuk transportasi yang banyak digunakan. Keuntungan utama angkutan di perairan adalah kemampuannya untuk membawa barang dalam jumlah besar. Kapal kayu telah mengalami berbagai macam modifikasi (Rauf \& Chaerunnisa, 2003). Hal ini dilakukan oleh para pengrajin kapal kayu berdasarkan teknik konstruksi yang mereka pahami sejak dahulu (Bochary \& Larengi, 2012). Konstruksi yang sepenuhnya berbahan kayu, umumnya diperoleh dari luar daerah, sehingga hal ini menjadi salah satu variabel yang mempengaruhi harga pembuatan kapal. Tidak hanya itu, material kayu tersebut hanya bisa didapatkan dari luar daerah dan jumlahnya pun relatif terbatas. Penebangan liar hutan di Indonesia yang tidak terbendung serta sangat merusak, mendorong pemerintah membuat regulasi tentang pembatasan penggunaan bahan kayu. Hal tersebut juga merupakan salah satu faktor yang menyebabkan kelangkaan material kayu. Masalah tersebut diperkuat dengan masih minimnya penggunaan bahan alternatif pengganti kayu sebagai bahan utama dalam pembuatan kapal kayu.

Menurut Soegiono (2006), gading-gading adalah salah satu anggota kerangka kapal melintang yang dipasang pada sisi kapal mulai dari bilge sampai geladak atau dari geladak sampai geladak di atasnya (Ayuningsari, 2007). Gading-gading merupakan tempat melekatnya kulit atau lambung kapal agar bentuknya tidak berubah. Gading-gading kapal kayu dibuat dari kayu yang melengkung secara alami, sehingga mudah untuk membentuknya seperti pada Gambar 1.

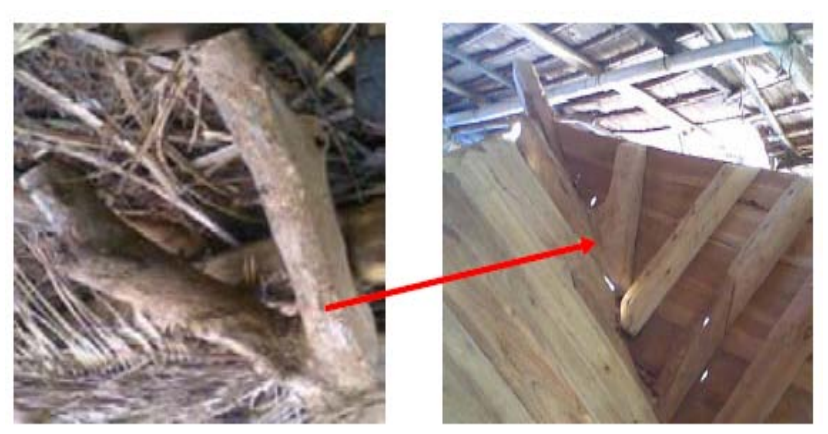

Gambar 1. Kayu lengkung peruntukan gading kapal

Bentuk kayu yang melengkung dapat memperkuat konstruksi kapal, karena arah serat kayu tidak ada yang berpotongan. Untuk gading lengkung dapat digunakan bahan dari kayu yang urat-uratnya sejalan dengan bentuk gadingnya. Bilamana kayu tersebut tidak cukup panjang, maka gading-gading dapat disambung (Biro Klasifikasi Indonesia, 1996).

Pada pembangunan kapal kayu 50-100 GT, gading merupakan salah satu konstruksi yang membutuhkan banyak bahan kayu setelah kulit lambung (Alamsyah, 2012). Gading-gading kapal kayu terbuat dari kayu Bitti (Karim dkk., 2011). Kayu Bitti (Vitex Cofassus Reinw) mempunyai 
elastisitas 9.534,02 MPa (Hapid, 2010), teksturnya melengkung secara alami sangat cocok untuk bahan dasar gading karena mudah dibentuk. Kayu lain yang digunakan untuk bahan konstruksi kapal kayu tradisional adalah kayu Gofasa (vitex cofassus) yang merupakan keluarga dari kayu Bitti, kayu ini masih lebih mudah ditemukan dari pada kayu Jati pada daerah berkapur (Lekatompessy dkk., 2019). Penggunaan kayu selain kayu Bitti untuk konstruksi gading menurut masyarakat pesisir pembuatan kapal pinisi akan memakan waktu dalam pembentukannya dan kekuatannya belum tentu sama. Ketersediaan kayu Bitti mulai langka, karena kurangnya peremajaan atau penanaman kembali, sehingga menyulitkan para pengrajin dalam membuat konstruksi gading-gading.

Pada penelitian sebelumnya bahan alternatif pengganti gading kayu seperti baja telah dicoba, selain sangat kuat dan tahan benturan, material ini sangat mudah didapatkan, namun terkendala pada proses perawatan (Bochary \& Larengi, 2012). Bahan lain seperti fiberglass reinforced plastic (FRP) yang telah banyak digunakan sebagai bahan alternatif pengganti kayu telah mendapat tempat tersendiri di dalam dunia perkapalan. Keuntungannya selain beratnya yang lebih ringan bahan FRP lebih tahan terhadap proses pelapukan sehingga usia atau masa pakai dari bahan FRP tentu lebih lama. Perawatan bahan FRP juga lebih mudah dan lebih minim. Selain itu, dengan ketebalan yang sama, konstruksi yang terbuat dari bahan FRP memiliki kekuatan yang lebih besar dibandingkan dengan konstruksi yang terbuat dari kayu. Oleh karena itu pada penelitian kali ini akan dicoba menggunakan teknologi bahan FRP sebagai pengganti kayu gading.

Konstruksi gading kayu Bitti yang melengkung sebagai bahan dasarnya, akan coba diganti dengan bahan FRP kemudian coba dianalisis kekuatannya dengan menggunakan software berbasis elemen hingga. Oleh karena itu, tujuan penelitian adalah mengetahui ukuran bahan FRP pengganti kayu gading yang sesuai dari segi kekuatan.

\section{METODE}

Penelitian ini memodelkan konstruksi setengah lebar kapal yang terdapat konstruksi gading serta konstruksi yang mengalami kontak langsung seperti: kulit, balok geladak, lunas, dan galar (senta) yang terletak pada midship section. Model pembebanan yang diberikan pada model konstruksi yakni beban merata pada trans deck beam dan beban trapezium pada gading. Material gading yang terbuat dari kayu Bitti, diganti dengan bahan FRP dengan berbagai bentuk penampang hasil rancangan yang sesuai dengan penampang yang ada pada kapal bahan FRP.

Data yang dikumpulkan dalam penelitian ini terdiri dari data primer dan data sekunder. Dalam penelitian ini, data primer yang dikumpulkan adalah main dimension kapal (70 GT) dengan LoA 23,19 m, B 4,8. m, H 2,10 m, gambar konstruksi kapal, ukuran detail penampang gading, dan spesifikasi kayu gading kapal. Data sekunder diperoleh dari studi literatur tentang gading kapal kayu, peraturan-peraturan dan dokumen hasil kajian literatur yang berhubungan dengan efisiensi material, bahan alternatif, serta kekuatan struktur kapal kayu.

Pada tahap pertama dilakukan identifikasi ukuran penampang gading kayu Bitti yang terpasang pada kapal kayu. Ukuran penampang kayu gading yang dijadikan sampel yakni yang terletak di midship section, karena tegangan terbesar terjadi di bagian tengah kapal. Ukuran konstruksi yang juga diidentifikasi adalah konstruksi yang mengalami kontak langsung dengan gading kapal kayu, seperti girder deck beam, transversal deck beam, galar serta lunas. Ukuran konstruksi ditunjukkan pada Gambar 2.

Hal lain yang dilakukan yakni studi literatur tentang efisiensi/pemanfaatan material gading kayu, keakuratan gading-gading dan bahan pengganti yang layak untuk kayu. Hal tersebut dilakukan untuk mengetahui perlunya ada teknologi pembangunan dalam menyiasati persediaan bahan untuk gading kayu yang mulai langka akibat kurangnya peremajaan dan penanaman kembali 
serta lebih menguatkan pada pemilihan bahan alternatif FRP sebagai bahan yang cocok sebagai pengganti kayu gading. Forest Products Laboratory (2010) digunakan sebagai literatur untuk mengetahui sifat mekanik dari material kayu.

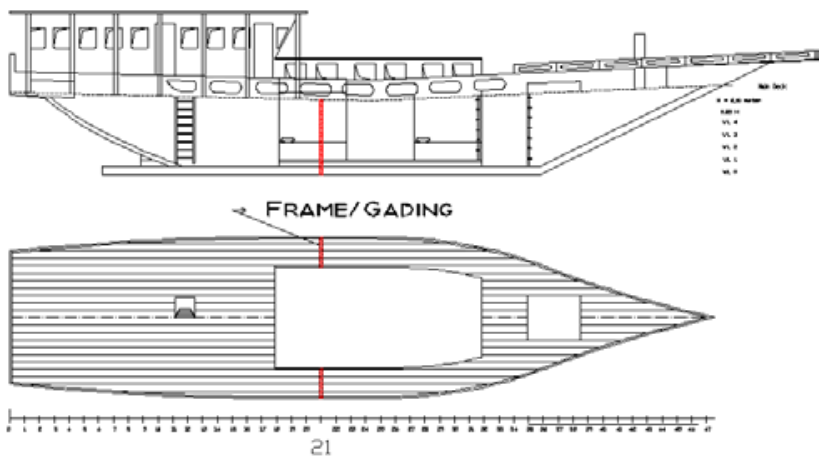

(a)

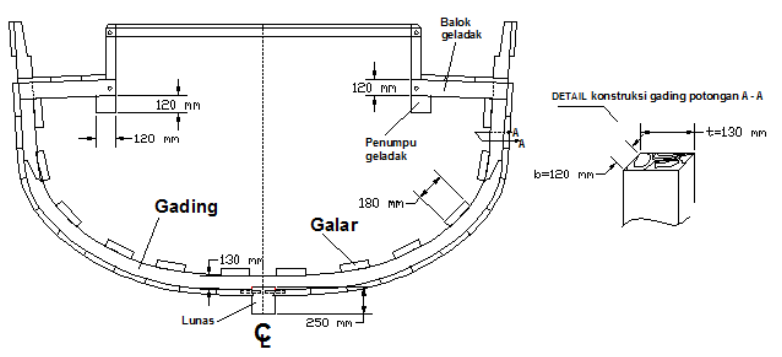

(b)

Gambar 2. a) Rencana umum kapal; b) Data konstruksi gading kapal (Alamsyah, 2012)

Penyederhanaan masalah dilakukan sebelum masuk pada model gading kayu dengan cara uji balok cantilever. Hal ini dilakukan untuk mengetahui kesetaraan antara balok cantilever kayu Bitti dengan balok cantilever FRP sebagai bahan pengganti kayu gading. Penampang yang dipilih untuk bahan FRP adalah I beam, I beam+flange, box of hole beam, $T$ beam, dan $U$ beam+Flange (Hashim, 1999). Bentuk penampang profil FRP ditunjukkan pada Gambar 3.

Pendekatan nilai tegangan maksimum dan lendutan maksimum menjadi dasar dalam pemilihan ukuran penampang FRP yang setara sebagai pengganti gading kayu. Menurut Leet \& Uang, (2005), untuk menganalisis tegangan maksimum dan lendutan maksimum pada balok cantilever digunakan persamaan:

$$
\sigma_{\max }=\frac{M . z}{I}
$$

$$
M=\frac{q \cdot l^{2}}{2}
$$
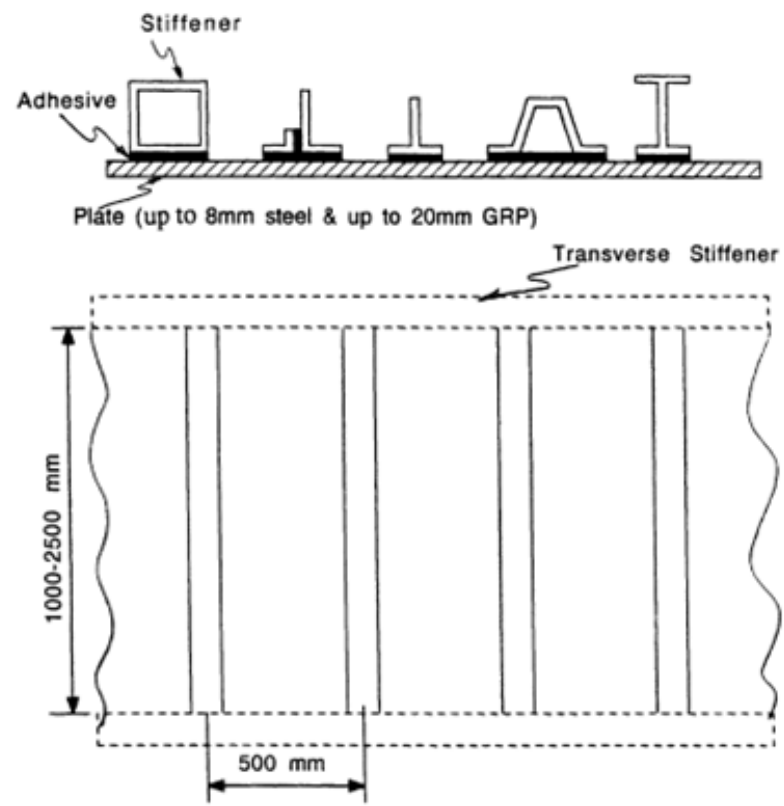

Gambar 3. Macam-macam model profil gading pada kapal fiberglass reinforced plastic (FRP) (Hashim, 1999)

$\sigma_{\max }=$ tegangan $\left(\mathrm{N} / \mathrm{mm}^{2}\right), M=$ momen maximum (N.mm), $l=$ panjang batang $(\mathrm{mm})$, $I=$ momen inersia penampang $\left(\mathrm{mm}^{4}\right), q=$ gaya (N/mm), dan $z=$ jarak terjauh dari sumbu neutral axis (mm). Dan untuk mendapatkan lendutan maksimum digunakan persamaan:

$$
\delta_{\max }=\frac{q \cdot l^{4}}{\varepsilon \cdot E}
$$

$\delta_{\max }=$ lendutan maksimum $(\mathrm{mm})$, $E=$ elastisitas $\left(\mathrm{N} / \mathrm{mm}^{2}\right), l=$ panjang batang $(\mathrm{mm})$, $I=$ momen inersia penampang $\left(\mathrm{mm}^{4}\right)$, dan $q$ = gaya $(\mathrm{N} / \mathrm{mm})$. Sedangkan untuk faktor keamanan (Sf) material dapat dihitung dengan menggunakan persamaan:

$$
S f=\frac{\sigma_{\text {yield }}}{\sigma_{\max }}
$$

$S f=$ faktor keamanan $(S f>1), \sigma_{\text {yield }}=$ tegangan luluh material $\left(\mathrm{N} / \mathrm{mm}^{2}\right)$, dan $\sigma_{\text {max. }}=$ tegangan kerja maksimum yang terjadi pada material konstruksi $\left(\mathrm{N} / \mathrm{mm}^{2}\right)$. Menurut Departemen Pekerjaan Umum (1961) dalam Peraturan Konstruksi Kayu Indonesia, kayu Bitti mempunyai tegangan luluh sebesar 9,8 N/mm² dan menurut Biro Klasifikasi Indonesia dalam (Budianto, 2015), tegangan luluh untuk bahan FRP sebesar $67 \mathrm{~N} / \mathrm{mm}^{2}$. 
Ukuran penampang material FRP yang dihasilkan dari hitungan manual dengan menggunakan persamaan (1), (2), (3), dan (4), kemudian dibawa ke uji coba model gading yang dianalisis dengan metode eksperimen numerik menggunakan bantuan perangkat komputer dengan piranti lunak (software) yang mengadopsi metode elemen hingga (FEM) pada sistem pemrogramannya. Software yang digunakan mampu mengeluarkan nilai tegangan yang terjadi pada struktur setelah diberikan beban eksternal, tujuannya untuk mencocokkan hasil analisis manual dan analisis software FE, agar lebih meyakinkan sebelum dimasukkan untuk disimulasikan pada pemodelan gading sebenarnya. Pada tahap pemodelan menggunakan software berbasis elemen hingga, gading dan konstruksi yang mengalami kontak langsung seperti longitudinal deck beam, transversal deck beam, galar, serta lunas akan dimodelkan ke dalam bentuk 3D sesuai dengan data awal yang didapatkan. Model pada software dapat dilihat pada Gambar 4.

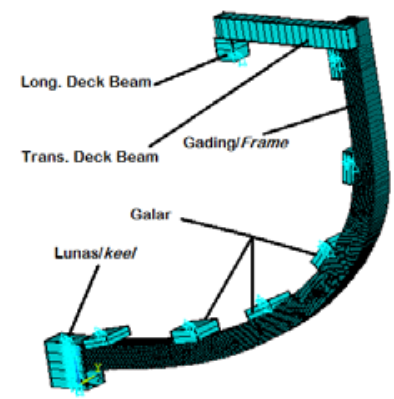

iading Rayu Profil Dox of square

Gambar 4. Pemodelan 3D gading kayu pada software FE

Simulasi model dilakukan dengan memberikan pembebanan sisi yang berbentuk trapesium dan pembebanan merata pada geladak. Untuk menentukan besar beban sisi pada lambung kapal dan beban merata pada geladak kapal dapat digunakan persamaan (5), (6) dan (7).

$$
Q=\rho \cdot g \cdot h \cdot a_{0}
$$

$Q=$ beban $(\mathrm{N} / \mathrm{mm}), \rho=$ berat jenis $\left(\mathrm{kg} / \mathrm{mm}^{3}\right)$, $\mathrm{g}=$ gravitasi bumi $\left(\mathrm{m} / \mathrm{s}^{2}\right), h=$ kedalaman kapal terhitung mulai dari tinggi kapal $\mathrm{H}+1000$ sebagai titik $0(\mathrm{~mm})$, dan $a_{0}=$ jarak gading (mm). Dalam analisa dilakukan penyederhanaan kasus menggunakan beban trapesium (line pressure) dapat dihitung dengan menggunakan persamaan berikut:

$$
Q_{\text {Total }}=\frac{Q_{1}}{Q_{2}}
$$

$Q_{\text {tot }}=$ jumlah 2 beban pada kedalaman tertentu $(\mathrm{N} / \mathrm{mm})$, dan $Q 1=Q 2=$ beban pada kedalaman tertentu $(\mathrm{N} / \mathrm{mm})$. Sementara untuk pembebanan geladak, nilainya dapat dihitung dengan persamaan yang diberikan oleh Rules for Hull BKI volume II section 4.B.1 (Biro Klasifikasi Indonesia, 2018):

$$
p_{D}=p_{0} \frac{20 . T}{(10+z-T) H} c_{D}
$$

$p_{D}=$ beban geladak kapal cuaca $\left(\mathrm{kN} / \mathrm{m}^{2}\right)$, $p_{0}=$ beban luar dinamis $=2,1(C b+0,7) \cdot C o \cdot C L . f$, sehingga $C b=$ koefisien blok, $C o=(L / 25+4,1)$. Crw untuk $L<90 \mathrm{~m}, C L=(L / 90)^{0,5}$ untuk $L<90 \mathrm{~m}$, $f=$ probability factor $(0,75), C r w=$ service range coefficient $=0,75$ (untuk pelayaran lokal), $c_{D}=$ koefisien distribusi, $\mathrm{z}=$ jarak vertikal pusat beban konstruksi terhadap garis dasar (m), $H=$ tinggi kapal (m), dan $T=$ sarat kapal (m). Proses input beban dan input peletakan diilustrasikan pada Gambar 5.

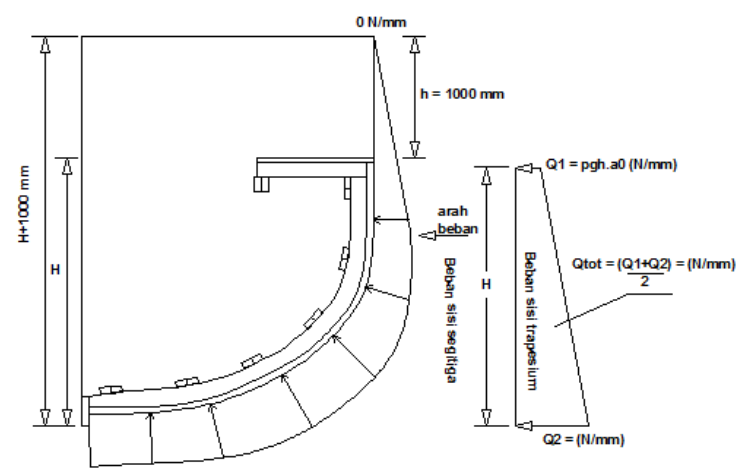

Gambar 5. Ilustrasi input beban dan perletakan pada gading kapal

Simulasi dilakukan terlebih dahulu pada kayu gading, tahap selanjutnya pada bahan FRP pengganti kayu gading dengan variasi penampang yang telah ditentukan sebelumnya, yakni penampang I beam, I beam+flange, box of hole beam, $T$ beam dan $U$ beam+flange. Tegangan maksimum, lendutan maksimum serta faktor 
keamanan akan menjadi objek utama perhatian dari hasil simulasi model. Pembebanan yang diberikan pada saat simulasi adalah pembebanan sisi berbentuk trapesium yang disebabkan oleh tekanan air laut dan pembebanan merata pada geladak. Tabel distribusi beban dapat dilihat pada Tabel 1 .

Tabel 1. Nilai beban yang diinput pada model

\begin{tabular}{ccc}
\hline $\begin{array}{c}\text { Ketinggian Sarat } \\
\text { di ukur dari buse } \\
\text { line }(\mathrm{mm})\end{array}$ & $\begin{array}{c}\mathrm{Q}= \\
\left(\text { p.g.h. } a_{0}\right)\end{array}$ & $\begin{array}{c}\text { Press Line } \\
\left(\mathrm{Q}_{\mathrm{tot}}\right)\end{array}$ \\
\cline { 3 - 3 }$(\mathrm{Qx}+\mathrm{Qxi}) / 2$ \\
\hline $2.100,00$ & 4,40 & \\
$1.866,72$ & 5,40 & 4,900 \\
$1.633,38$ & 6,46 & 5,930 \\
$1.400,04$ & 7,49 & 6,975 \\
$1.166,7$ & 8,51 & 8,000 \\
933,36 & 9,54 & 9,025 \\
700,02 & 10,56 & 10,050 \\
466,68 & 11,59 & 11,075 \\
233,34 & 12,61 & 12,100 \\
0 & 13,64 & 13,125 \\
\hline
\end{tabular}

\section{HASIL DAN PEMBAHASAN}

Hasil analisis kekuatan yang didapatkan dengan menggunakan FE pada simulasi model menunjukkan bahwa tegangan maksimum yang terjadi pada kayu gading (kayu Bitti) dengan elastisitas 9534,02 MPa dan momen inersia penampang $2.197 \times 10^{4} \mathrm{~mm}^{4}$ yakni, nilai tegangan maksimum sebesar 7,682 N/mm² dan lendutan maksimum sebesar 0,109 mm. Tegangan yang dihasilkan tidak melebihi tegangan luluh material kayu sebesar 9,8 N/mm² dan faktor keamanan yang dikeluarkan yakni 1,28. Faktor keamanan dari gading kayu tersebut akan menjadi patokan pada model bahan fiberglass reinforced plastic sebagai pengganti kayu gading. Hasil simulasi software untuk gading ditunjukkan pada Gambar 6.

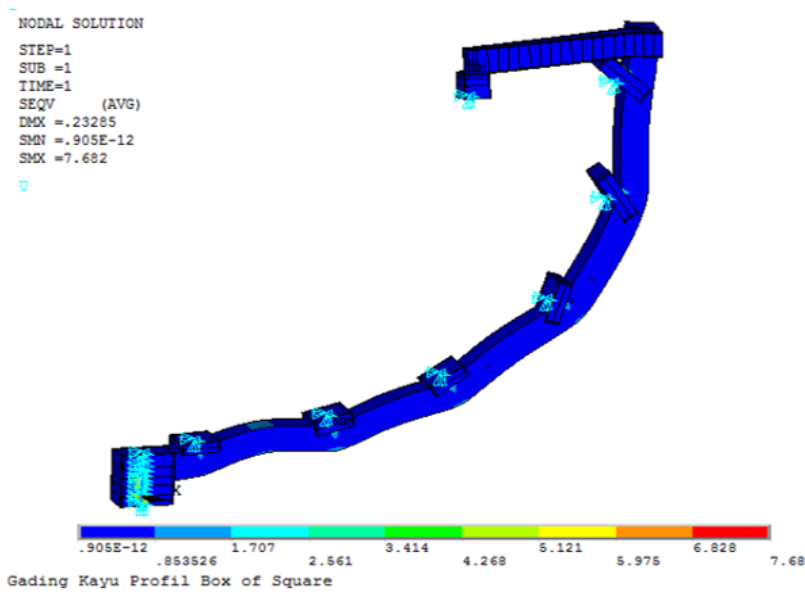

Gambar 6. Hasil running software FE terhadap gading kapal material kayu Bitti

Untuk bahan FRP pengganti kayu gading setelah simulasi model menunjukkan bentuk penampang $I$ beam dengan momen inersia penampang sebesar $316 \times 10^{4} \mathrm{~mm}^{4}$ menghasilkan tegangan maksimum sebesar 52,385 N/mm² dengan lendutan maksimum sebesar 0,0504 mm. Untuk FRP 2 penampang $I$ beam+flange yang memiliki momen inersia penampang sebesar $288 \times 10^{4} \mathrm{~mm}^{4}$ menghasilkan tegangan maksimum sebesar 52,40 $\mathrm{N} / \mathrm{mm}^{2}$ dengan lendutan maksimum sebesar 0,082 mm. Untuk FRP 3 penampang box of hole beam dengan Inersia $317 \times 10^{4} \mathrm{~mm}^{4}$ menghasilkan tegangan maksimum 52,48 N/mm² dengan lendutan maksimumnya sebesar $0,047 \mathrm{~mm}$. Untuk FRP 4 penampang $T$ beam dengan Inersia $478 \times 10^{4} \mathrm{~mm}^{4}$ menghasilkan tegangan maksimum sebesar 52,48 $\mathrm{N} / \mathrm{mm}^{2}$ dengan lendutan maksimum sebesar 0,027 mm. Dan untuk FRP 5 penampang $U$ beam+flange dengan inersia $375 \times 10^{4} \quad \mathrm{~mm}^{4}$ menghasilkan tegangan sebesar 52,44 N/ $\mathrm{mm}^{2}$ dengan lendutan maksimum sebesar 0,039 mm, sedangkan elastisitasnya bernilai $69.000 \mathrm{MPa}$ yang berlaku untuk semua penampang FRP.

Faktor keamanan pada gading kayu dijadikan ketetapan yang harus dipenuhi gading FRP dengan nilai faktor keamanan sebesar 1,28. Proses pemodelan gading bahan FRP untuk salah satu penampang pengganti kayu gading sebelum dan setelah diberikan pembebanan dapat dilihat pada Gambar 7. 


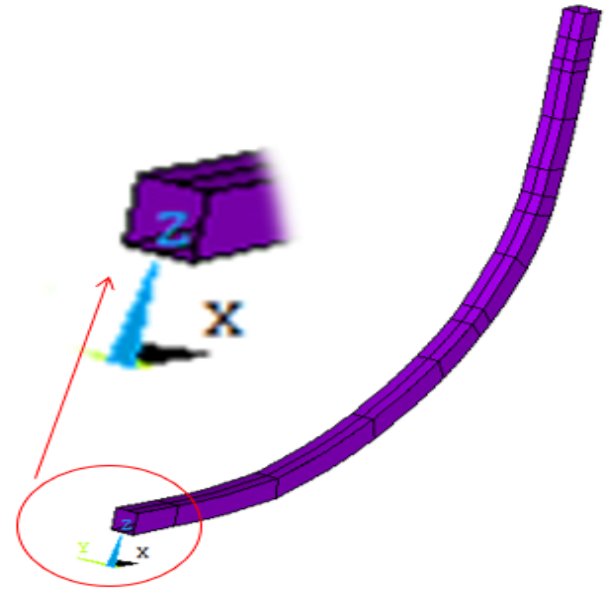

Gading Fiberglass 3 Profil Box of Hole

(a)

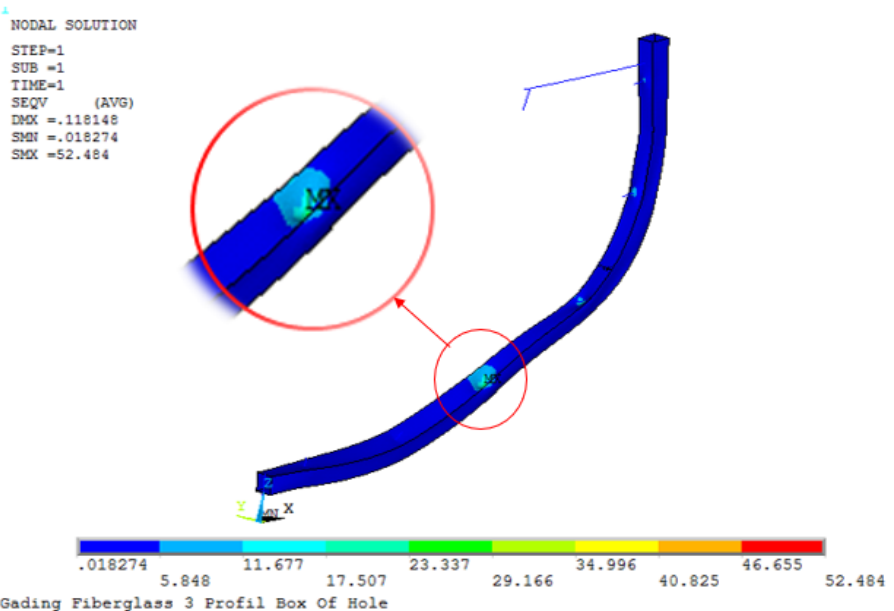

(b)

Gambar 7. a) Gambar pemodelan 3D salah satu penampang gading FRP pada software FE; b) Hasil running software FE terhadap gading kapal material FRP

Tabel 2. Hasil uji coba bahan fiberglass reinforced plastic sebagai pengganti kayu gading

\begin{tabular}{|c|c|c|c|c|c|c|}
\hline \multirow{2}{*}{$\begin{array}{c}\text { Nilai Properties dan } \\
\text { Hasil } \\
\text { Pengamatan }\end{array}$} & \multirow[b]{2}{*}{ Kayu Bitti } & \multicolumn{5}{|c|}{ Fiberglass Reinforced Plastic (FRP) } \\
\hline & & I-Beam & $\begin{array}{l}\text { I-Beam+ } \\
\text { Flange }\end{array}$ & $\begin{array}{c}\text { Box of } \\
\text { Hole-Beam }\end{array}$ & T-Beam & $\begin{array}{l}\text { U-Beam } \\
+ \text { Flange }\end{array}$ \\
\hline Elastisitas (E) $\left(\mathrm{N} / \mathrm{mm}^{2}\right)$ & $9.534,02$ & 69.000 & 69.000 & 69.000 & 69.000 & 69.000 \\
\hline Inersia (I) $\left(\mathrm{mm}^{4}\right)$ & $2,197 \times 10^{7}$ & $3,160 \times 10^{6}$ & $2,880 \times 10^{6}$ & $3,170 \times 10^{6}$ & $4,780 \times 10^{6}$ & $3,750 \times 10^{6}$ \\
\hline Berat jenis $(\rho)\left(\mathrm{kg} / \mathrm{m}^{3}\right)$ & 800 & 2.600 & 2.600 & 2.600 & 2.600 & 2.600 \\
\hline $\mathrm{EI}\left(\mathrm{N} \cdot \mathrm{mm}^{2}\right)$ & $2,09462 \times 10^{11}$ & $2,1800 \times 10^{11}$ & $1,9870 \times 10^{11}$ & $2,1873 \times 10^{11}$ & $3,2980 \times 10^{11}$ & $2,5880 \times 10^{11}$ \\
\hline $\begin{array}{l}\text { Tegangan luluh }(\sigma \mathrm{i}) \\
\left(\mathrm{N} / \mathrm{mm}^{2}\right)\end{array}$ & 9,8 & 67 & 67 & 67 & 67 & 67 \\
\hline $\begin{array}{l}\text { Tegangan max. pada } \\
\text { node }(\sigma n)\left(\mathrm{N} / \mathrm{mm}^{2}\right)\end{array}$ & 7,682 & 52,358 & 52,402 & 52,484 & 52,300 & 52,437 \\
\hline Lendutan $(\delta)(\mathrm{mm})$ & 0,1090 & 0,0504 & 0,0820 & 0,0470 & 0,0270 & 0,0390 \\
\hline $\begin{array}{l}\text { Jarak terjauh dari }(\mathrm{z}) \\
\text { netral axis }(\mathrm{mm})\end{array}$ & 65.000 & 50,00 & 52,23 & 48,05 & 90,95 & 49,83 \\
\hline Ketebalan (t) (mm) & 130 & 7,35 & 6,57 & 7,40 & 16,72 & 7,53 \\
\hline
\end{tabular}


Dengan melihat data tegangan dan lendutan yang terjadi dan keluaran dari simulasi model menggunakan software berbasis elemen hingga setelah dianalisis menunjukkan bahwa dibutuhkan bahan FRP yang memiliki elastisitas yang jauh lebih besar serta momen inersia penampang yang jauh lebih kecil untuk menggantikan bahan kayu gading. Hasil analisis data dapat dilihat pada Tabel 2.

Penelitian ini menunjukkan bahan FRP yang sesuai dari segi kekuatan menggantikan kayu gading yakni memiliki momen inersia penampang sebesar 1/9 1/5 kali lebih kecil dari momen inersia penampang kayu gading dengan nilai elastisitas 7 kali lebih besar dari elastisitas kayu gading. Pada profil FRP 1 (I beam) terjadi penambahan momen inersia penampang sebesar 27,9\% dari hasil uji coba model balok cantilever menuju uji coba model gading. Untuk profil FRP 2 (I beam+flange) terjadi penambahan momen inersia penampang sebesar $11,5 \%$ dari hasil uji coba model balok cantilever menuju uji coba model gading. Untuk profil FRP 3 (box of hole beam) terjadi penambahan momen inersia penampang sebesar 33,8 \% dari hasil uji coba model balok 10 cantilever menuju uji coba model gading. Untuk profil FRP 4 ( $T$ beam) terjadi penambahan mom en inersia penampang sebesar 8,38 \% dari hasil uji coba model balok cantilever menuju uji coba model gading, sementara untuk profil FRP 5 (U beam+flange) terjadi penambahan momen inersia penampang sebesar 63,8 \% dari hasil uji coba model balok cantilever menuju uji coba model gading.

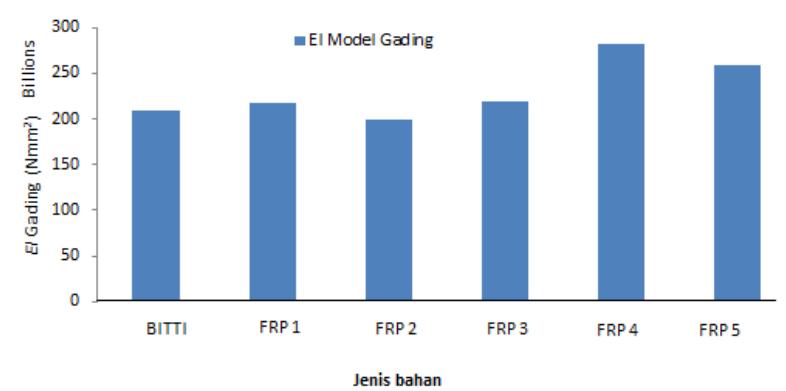

Gambar 8. Nilai $E I_{\text {kayu }}$ dan $E I_{\text {FRP }}$ pada model masing-masing gading

Jika dirata-ratakan kenaikan nilai momen inersia penampang dari ke-5 penampang bahan FRP pengganti kayu gading adalah sebesar 29,1 \%. Hal ini dilakukan karena untuk memenuhi faktor keamanan kayu gading sebesar 1,28, atau dengan kata lain kesetaraan antara kekuatan kayu gading dan bahan FRP pengganti kayu gading tercapai. Perbandingan nilai $E I_{\text {kayu }}$ dan $E I_{\mathrm{FRP}}$ pada model masing-masing gading dapat dilihat seperti pada Gambar 8.

\section{KESIMPULAN}

Untuk bahan FRP pengganti kayu gading penampang I beam membutuhkan momen inersia penampang sebesar $316 \times 10^{4} \mathrm{~mm}^{4}$. Untuk FRP 2 penampang I beam+flange membutuhkan momen inersia penampang sebesar $288 \times 10^{4} \mathrm{~mm}^{4}$. Untuk FRP 3 penampang box of hole beam membutuhkan momen inersia $317 \times 10^{4} \mathrm{~mm}^{4}$. Untuk FRP 4 penampang $T$ beam membutuhkan momen inersia $478 \times 10^{4} \mathrm{~mm}^{4}$. Dan untuk FRP 5 penampang $U$ beam+flange membutuhkan momen inersia $375 \times 10^{4} \mathrm{~mm}^{4}$, sedangkan elastisitasnya bernilai 69.000 MPa yang berlaku untuk semua penampang FRP. Faktor keamanan pada gading kayu dijadikan ketetapan yang harus dipenuhi gading FRP dengan nilai faktor keamanan sebesar 1,28. Dari penelitian ini, kesimpulan yang dapat diambil terkait permasalahan kelangkaan bahan dasar konstruksi gading kapal kayu dapat diatasi dengan menggunakan bahan FRP pengganti kayu gading yang mempunyai momen inersia penampang sebesar 1/7 1/5 kali lebih kecil dari momen inersia penampang kayu gading dengan elastisitas 7 kali lebih besar dari kayu gading. Nilai ini dapat dijadikan patokan untuk ukuran kapal di atas ataupun di bawah 70 GT ketika akan menggunakan bahan FRP sebagai pengganti gading kayu.

\section{UCAPAN TERIMA KASIH}

Ungkapan terima kasih kepada pusat kemaritiman LPPM ITK yang telah memfasilitasi penelitian ini dan reviewer Jurnal Wave yang tidak diketahui namanya sehingga paper ini layak diterbitkan. 


\section{DAFTAR PUSTAKA}

Abbas, M. A. (2001). Pinisi: Perahu Khas Sulawesi Selatan. Makassar: Proyek Pembinaan Peninggalan Sejarah Purbakala dan Permuseuman Sulawesi Selatan.

Alamsyah. (2012). Analisis Penggunaan Material Kayu pada Pembangunan Kapal Kayu (GT 50-100). Skripsi. Universitas Hasanuddin.

Ayuningsari, D. (2007). Tekno-Ekonomi Pembangunan Kapal Kayu Galangan Kapal Rakyat di Desa Gebang, Cirebon, Jawa Barat. Skripsi. Institut Pertanian Bogor.

Biro Klasifikasi Indonesia. (1996). Buku Peraturan Klasifikasi dan Konstruksi Kapal Laut Peraturan Kapal Kayu (p. 91). Jakarta: Biro Klasifikasi Indonesia.

Biro Klasifikasi Indonesia. (2018). Volume II Rules for Hull. In Part 1 Seagoing Ships. Jakarta: Biro Klasifikasi Indonesia.

Bochary, L., \& Larengi, F. (2012). Alternatif Penggunaan Gading Baja pada Pembangunan Kapal Kayu 30 GT. Jurnal Riset dan Teknologi Kelautan, 10(2), 145-156.

Budianto. (2015). Analisis Kekuatan Struktur pada Kapal Wisata Sungai Kalimas. Kapal, 12(1), 9-18.

Departemen Pekerjaan Umum. (1961). Peraturan Konstruksi Kayu Indonesia. Jakarta: Departemen Pekerjaan Umum.

Forest Products Laboratory. (2010). Wood Handbook-Wood as an Engineering Material (Centennial ed.). Madison: United States
Department of Agriculture Forest Service.

Hapid, A. (2010). Struktur Anatomi dan Sifat Fisika-Mekanik Kayu Bitti (Vitex Cofassus Reinw) dari Hutan Rakyat yang Tumbuh di Kabupaten Bone dan Wajo Sulawesi Selatan. Thesis. Universitas Gadjah Mada.

Hashim, S. A. (1999). Adhesive Bonding of Thick Steel Adherends for Marine Structures. Marine Structures, 12(6), 405-423.

Karim, A. A., Hasbullah, M., Muhammad, A. H. (2011). Kajian Dimensi dan Model Sambungan Konstruksi Kapal Kayu Produksi Galangan Rakyat di Kabupaten Bulukumba. Prosiding Hasil Penelitian Fakultas Teknik Universitas Hasanuddin, 1-8.

Leet, K. M., \& Uang, C.-M. (2005). Fundamental of Structure Analysis (Second Edition). Oakland: University of California.

Lekatompessy, D. R., Soumokil, R. P., \& Ririmasse, H. C. (2019). Analisa Response Dinamik pada Sambungan Konstruksi Kapal Kayu Berdasarkan Tipe Mesin yang Digunakan. Archipelago Engineering 2019, 26-30.

Rauf, A. M., \& Chaerunnisa, A. (2003). Pengembangan Metode Pembuatan Kapal Kayu Tradisional di Kabupaten Bulukumba. Makassar: Lembaga Penelitian dan Pengembangan Masyarakat Universitas Hasanuddin.

Soegiono. (2006). Kamus Teknik Perkapalan (Edisi keempat ed.). Surabaya: Airlangga University Press. 
Kekuatan Fiberglass Reinforced Plastic (FRP) sebagai Bahan Gading Kapal Kayu (Alamsyah, Rodlian Jamal Ikhwani, Taufik Hidayat, dan Suardi)

HALAMAN KOSONG 